\title{
EFFECTS OF ADRENALINE, OUABAIN, AND SOME IONIC CONDITIONS ON TWITCH CONTRACTION OF BULLFROG VENTRICLE
}

\author{
Tsuguhisa EHARA \\ Department of Physiology, School of Medicine, Kyushu University, Fukuoka, Japan
}

Summary 1) The effects of adrenaline, ouabain, low-K Ringer, and low-Na Ringer on the time course of twitch contraction were studied in the ventricular preparations of bullfrog, with special reference to their effects on relaxation.

2) Adrenaline $\left(10^{-7}-10^{-6} \mathrm{~g} / \mathrm{ml}\right)$ had the effect of enhancing the relaxation of twitch, in addition to its potentiating effect.

3) Ouabain $\left(10^{-7}-10^{-6} \mathrm{M}\right)$ only potentiated the twitch without an appreciable effect on the relaxation phase.

4) Low-K Ringer $(0.16 \mathrm{~mm}-\mathrm{K})$, as well as low-Na Ringer $(50 \%-\mathrm{Na})$, reduced the rate of relaxation of twitch.

5) Low-Na Ringer had an additional effect to shorten the time to maximum rate of rise of tension.

6) These effects were evaluated quantitatively by an analysis in which the increase in the rate of fall of tension was compared with the increase in peak tension or with the increase in the rate of rise of tension.

7) Possible subcellular mechanisms to explain the results were discussed.

In myocardium, the increase in sarcoplasmic activator $\mathrm{Ca}$ which is responsible for initiation of contraction is thought to be brought about by an inflow of $\mathrm{Ca}$ across the sarcolemma and/or by a Ca release from the sarcotubular system (for review, see LANGER, 1973). In contrast, during relaxation, the increased ionic $\mathrm{Ca}$ is thought to be reduced by a $\mathrm{Ca}$ uptake of sarcotubular system and/or by some mechanism for $\mathrm{Ca}$ extrusion across the sarcolemma (REUTER and SEITZ, 1968; GLITSCH et al., 1970; Gото et al., 1972b). Many agents and conditions effective on myocardial contractility, such as catecholamines and cardiac glycosides, are generally presumed to alter some kinetics of activator $\mathrm{Ca}$ during a contraction cycle. The subcellular mechanisms underlying their actions, however, do not seem to be fully understood. These agents may have actions either on the process of liberating or transporting the activator $\mathrm{Ca}$ into myoplasm, or on the process of

Received for publication March 22, 1974

頴原嗣尚 
reducing it after activation of contraction, or on both.

In the present experiments, the effects of adrenaline and ouabain and some ionic conditions known to increase the myocardial contractility were studied in bullfrog ventricle, with special attention to their effects on the falling phase of twitch contraction. A preliminary note of the results has already been published (EHARA, 1973).

\section{METHODS}

Thin strips (diameter $1-1.5 \mathrm{~mm}$ ) of the ventricular wall dissected from the heart of bullfrog (Rana catesbiana) were used. Care was taken to remove ventricular pacemaker tissue. The strips were mounted in a recording chamber $(1.5 \mathrm{ml}$ in volume) which was continuously perfused with normal or test solutions at $19-20^{\circ} \mathrm{C}$. A pair of large $\mathrm{Ag}-\mathrm{AgCl}$ electrodes were used for massive field stimulation, and the muscles were driven with a square pulse of $5 \mathrm{msec}$ duration at a constant frequency of 10 shocks per min. The twitch tension was measured isometrically with a mechano-electric transducer (Shinko, UL-120) attached to one end of the muscle. The rate of rise and fall of tension were also recorded by electronic differentiation (RC circuit, time const. $15 \mathrm{msec}$ ).

Normal Ringer solution was composed of (mM/liter) $\mathrm{NaCl} 70.8, \mathrm{KCl} 2.5$, $\mathrm{Na}_{2} \mathrm{SO}_{4}$ 2.1, Na-gluconate 1.9, $\mathrm{NaHCO}_{3}$ 25.0, $\mathrm{Na}_{2} \mathrm{HPO}_{4}$ 3.0, $\mathrm{CaCl}_{2}$ 1.0, $\mathrm{MgCl}_{2}$ 1.2 , and glucose 21.0 . $50 \%-\mathrm{Na}$ Ringer solution was made by replacing $53.9 \mathrm{~mm}$ $\mathrm{NaCl}$ with an osmotically equivalent amount of sucrose or $\mathrm{LiCl}$ or choline chloride. In the choline Ringer solution, atropine sulphate $\left(10^{-5} \mathrm{M}\right)$ was added to eliminate the parasympathomimetic action of choline chloride. In low-K Ringer solution, $\mathrm{KCl}$ was reduced to $0.16 \mathrm{~mm}$ and the tonicity was compensated with glucose. All solutions were equilibrated with a gas mixture of $95 \% \mathrm{O}_{2}+5 \% \mathrm{CO}_{2}$. Inotropic agents used were adrenaline $\left(10^{-7}-10^{-6} \mathrm{~g} / \mathrm{ml}\right)$ and ouabain $\left(10^{-7}-10^{-6} \mathrm{M}\right)$.

The muscle was initially driven in normal Ringer solution for $1-1.5 \mathrm{hr}$ until the twitch tension became steady, and then the bathing fluid was exchanged for test solution. The developed tension and its differential were monitored on a dual beam oscilloscope and photographed with a recording camera.

\section{RESULTS}

\section{The normal pattern of twitch contraction}

The present examination was mainly concerned with the alterations in the pattern of twitch contraction which occurred under some inotropic interventions. The first step of the experiment was to study the normal pattern of twich in the bullfrog ventricle, and five parameters, i.e. peak tension $(T)$, maximum rate of rise of tension $\left(V_{c}\right)$, maximum rate of fall of tension $\left(V_{r}\right)$, time to peak tension $\left(t_{p}\right)$ and time to maximum rate of rise of tension $\left(t_{m}\right)$ were used for convenient 


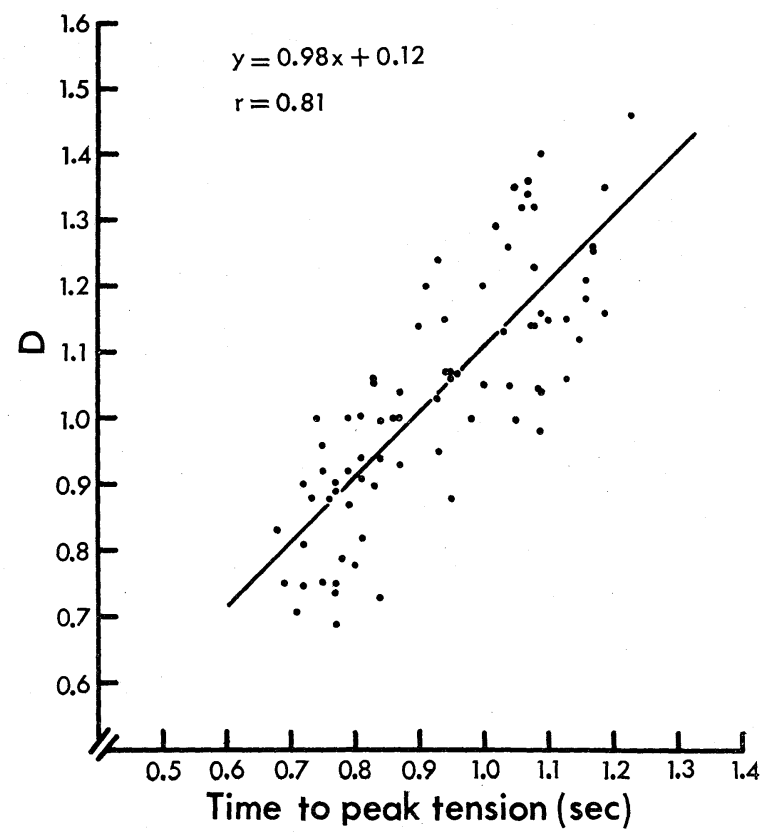

Fig. 1. Correlation between $D$ (the ratio between maximum rate of fall of tension and maximum rate of rise of tension) and time to peak tension observed in normal twitches of 79 bullfrog ventricles. The correlation coefficient was 0.81 . The regression line $(y=0.98 x+0.12)$ was obtained from the method of least squares.

description of the twitch pattern. The ratio between $V_{r}$ and $V_{c}$ was also used and expressed as $D$.

Figure 1 shows the relationship between $D$ and $t_{p}$ obtained from 79 preparations under normal conditions. Although the values of both $D$ and $t_{p}$ appeared considerably spread, it was found that the muscles which exhibited long $t_{p}$ tended to show comparatively large $D$, and vice versa, as seen in the figure. The correlation coefficient between $D$ and $t_{p}$ was 0.81 and the regression line calculated from the method of least squares was;

$$
D=0.98 t_{p}+0.12
$$

The mean values of $D$ and $t_{p}$ were $1.04 \pm 0.18$ S.D. and $0.93 \pm 0.15$ S.D. (sec), respectively. The implication of the relationship described here will be discussed later.

Effects of adrenaline and ouabain on the twitch pattern

There was a considerable difference between adrenaline and ouabain with respect to the time required for their action. Adrenaline, when applied to the muscle, immediately potentiated the contraction, whereas ouabain required more than $1 \mathrm{hr}$ for its full activation. A similar but reverse phenomenon was observed after washing. As can be seen in Fig. 2, which shows the typical results, the 

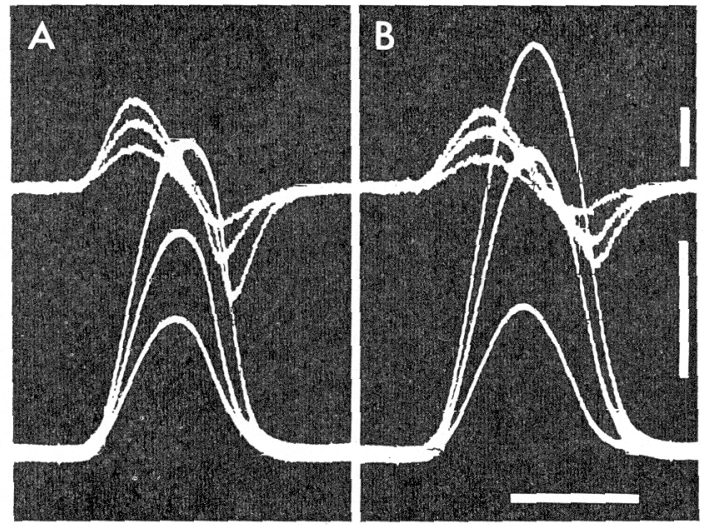

Fig. 2. Superimposed records of twitch contractions in bullfrog ventricle before and after exposure to Ringer solution containing adrenaline $10^{-7} \mathrm{~g} / \mathrm{ml}$ (A) and ouabain $10^{-6} \mathrm{M}$ (B). Upper traces are differential curves of contractions. In each figure, control and the full potentiated state, with an intermediate, are shown. Upper vertical bar is calibration of $200 \mathrm{mg} / \mathrm{sec}$, lower one, that of $60 \mathrm{mg}$ for A and $40 \mathrm{mg}$ for B. Horizontal bar, calibration of $1 \mathrm{sec}$. Note that the rate of relaxation is enhanced under adrenaline.

positive inotropic effects of adrenaline $\left(10^{-7} \mathrm{~g} / \mathrm{ml}\right)$ and ouabain $\left(10^{-6} \mathrm{M}\right)$ were mainly due to an increase in the rate of rise of tension, although time to peak tension $\left(t_{p}\right)$ was slightly prolonged. The rate of fall of tension was also augmented with increase in peak tension in both cases. In the adrenaline media, however, the increase in maximum rate of fall of tension $\left(V_{r}\right)$ appeared to be greater than that in the maximum rate of rise of tension $\left(V_{c}\right)$, while they seemed almost the same in ouabain media. In consequence, under adrenaline, the total contraction time was not lengthened in spite of the prolonged $t_{p}$.

These effects of adrenaline and ouabain were examined repeatedly in a number of preparations, and the results are summarized in Fig. 3 and Table 1. The concentration of drugs was varied between $10^{-7}-10^{-6} \mathrm{~g} / \mathrm{ml}$ with adrenaline and between $10^{-7}-10^{-6} \mathrm{M}$ with ouabain. The sensitivity of muscles to adrenaline was quite fluctuant among the preparations, and a consistent relationship between dose and inotropic response was hardly obtained. In the ouabain media, however, the dose-response relationship was quite consistent, and the larger the dose, the stronger the potentiation became in most preparations. Figure 3 shows the relationship between the increase of $V_{r}$ and that of $T$ obtained under adrenaline or ouabain. In this figure, the values relative to control are plotted. It can be seen that the increase in $V_{r}$ and the increase in $T$ were almost equal under ouabain so that the data scattered along the reference line $y=x$. On the other hand, adrenaline increased $V_{r}$ relatively more than $T$ in most preparations so that the most data scattered above the line $y=x$. The effect of ouabain seemed independent of the degree of potentiation, whereas it was noted that the relaxation-facilitating effect of adrenaline was less prominent in the muscles which were strongly 
potentiated, as seen in Fig. 3. Quantitatively, the ratio between relative $V_{r}$ and relative $T$ was $1.16 \pm 0.13$ S.D. $(n=22)$ in adrenaline media and $1.03 \pm 0.07$ S.D. $(n=17)$ in ouabain media. The former was significantly larger than $1(P<0.001)$ and the latter, not significantly different from $1(P>0.1)$.

On the other hand, $t_{p}$ tended to increase both under adrenaline and under ouabain (Table 1). Adrenaline lengthened $t_{p}$ by $10 \%$, and ouabain, by $9 \%$.

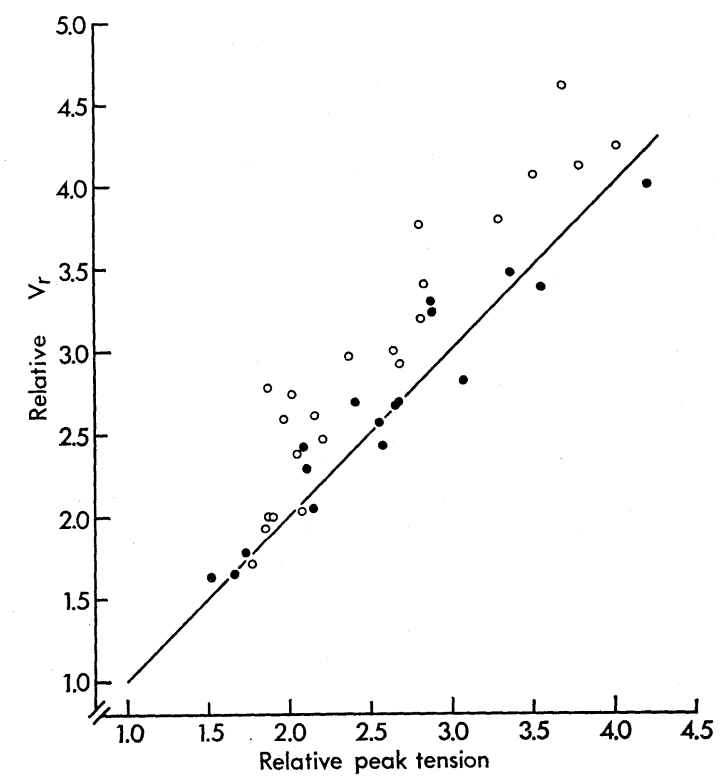

Fig. 3. Relationship between peak tension and maximum rate of fall of tension $\left(V_{r}\right)$ obtained from bullfrog ventricle under adrenaline (open circles) and ouabain (closed circles). Each point represents the response of one muscle and the value is expressed as relative to control. The concentration of adrenaline was $10^{-7}-10^{-6} \mathrm{~g} / \mathrm{ml}$ and that of ouabain, $10^{-7}-10^{-6} \mathrm{M}$. The line, $y=x$, is drawn for reference.

Table 1. Changes in contraction parameters in response to adrenaline and ouabain.

\begin{tabular}{|c|c|c|c|c|}
\hline & & $t_{p}$ & $t_{m}$ & $D$ \\
\hline Adrenaline & $\begin{array}{l}10^{-7}-10^{-6} \mathrm{~g} / \mathrm{ml} \\
\text { (22) }\end{array}$ & $1.10^{* *} \pm 0.05$ & $1.05^{*} \pm 0.09$ & $1.19 * * \pm 0.12$ \\
\hline Ouabain & $\begin{array}{l}10^{-7}-10^{-6} \mathrm{M} \\
\text { (17) }\end{array}$ & $1.09 * * \pm 0.05$ & $1.01 \pm 0.07$ & $1.05^{*} \pm 0.08$ \\
\hline
\end{tabular}

Values relative to control, with S.D., are presented in all columns. $t_{p}$, time to peak tension; $t_{m}$, time to maximum rate of rise of tension; $D$, ratio between maximum rate of fall of tension and maximum rate of rise of tension. Numbers in parentheses are the number of experiments. Values significantly different from 1.00 are symbolized with $*(P<0.02)$ and $* *(P<0.001)$. 
At the same time, adrenaline increased $t_{m}$ by $5 \%$ and this was a significant increase $(P<0.02)$, while $t_{m}$ under ouabain did not change significantly.

Next, a comparison was made between the increase in $V_{r}$ and that in $V_{c}$ under similar conditions. However, when at first the increase in $V_{r}$ was simply compared with that in $V_{c}$, the former was generally larger than the latter even under ouabain as well as under adrenaline. Therefore, the relative value of $D$ became larger than 1 in both cases (Table 1). It must be taken into considerations, however, that the change in $t_{p}$ per se might influence the twitch pattern. If certain assumptions are allowable, the effects of drugs on the twitch pattern can be evaluated, the influence of the change in $t_{p}$ being appropriately excluded.

In the recent experiments of current clamp where myocardial action potential was artificially shortened or lengthened by polarization (MORAD and TRAUTWEIN, 1968; KAWATA et al., 1969; ANTONi et al., 1969), it was shown that a partial abbreviation or a prolongation of action potential around the normal duration produced a change in $t_{p}$ which accompanied a certain change in $T$. In this case, $V_{c}$ was never affected. Similar results have been obtained in the experiments of voltage clamp on frog ventricle (GoTO et al., 1971; MORAD and ORKAND, 1971) where the duration of controlled depolarization was changed around a period comparable to the duration of normal action potential. Therefore, it was assumed for simplicity that there is a linear relationship between $T$ and $t_{p}$ so long as the change in $t_{p}$ is sufficiently small. The assumption is expressed in differential as follows;

$$
\Delta T \propto \Delta t_{p}
$$

where $\Delta T$ and $\Delta t_{p}$ are changes in $T$ and $t_{p}$, respectively.

On the other hand, the rate of fall of myocardial twitch tension increases with increase in $T$ under variable conditions. This common phenomenon could be explained by assuming a simple first order kinetics for the movement of activator $\mathrm{Ca}$ during relaxation. The prediction implies that the activator $\mathrm{Ca}$, on which tension depends, is removed from certain sites or region at a constant rate whether its concentration is high or low. In such a system, $V_{r}$ should be proportional to T. This view was supported recently by Goто et al. (1972b) who observed with voltage clamp experiments that, in the contractions of frog atrium produced by controlled depolarization of various magnitude, $V_{r}$ was proportional to $T$. Therefore, it was assumed that;

$$
V_{r} \propto T
$$

It is interesting that, in the present experiments, ouabain increased $V_{r}$ in parallel with $T$ (Fig. 3), and this result can be suitably explained by the prediction described above.

When Eqs. (2) and (3) are combined, we obtain a relationship;

$$
\Delta V_{r} \propto \Delta t_{p}
$$

where $\Delta V_{r}$ is a change in $V_{r}$. Provided the change in $t_{p}$ is small enough to produce no effect on $V_{c}$ (MORAD and TraUtWein, 1968; KaWATA et al., 1969), the relation- 
ship between $D$ and $t_{p}$ can be given by

$$
D=V_{r} / V_{c}=a t_{p}+b
$$

where $a$ and $b$ are constants. This equation describes how a small change in $t_{p}$ affects the twitch pattern, and coincides well with the data shown before (Fig. 1, Eq. 1).

When $a$ and $b$ are taken to be 0.98 and 0.12 , respectively, as obtained in Fig. 1, one can use Eq. (5) and approximate the change in $D$ expected from the change in $t_{p}$ which occurred under adrenaline or ouabain, since the mean value of $D$ in control and the mean change in $t_{p}$ were obtained from the experiments (Table 1). Thus, the expected increase in $D$ calculated from Eq. (5) was $11 \%$ under adrenaline and $10 \%$ under ouabain, while the observed increase in $D$ was $19 \pm 12 \%$ S.D. and $5 \pm 8 \%$ S.D., respectively. The observed value was significantly larger than the expected one under adrenaline $(P<0.01)$, whereas there was no significant difference under ouabain. These results indicate that adrenaline increased $V_{r}$. much more than $V_{c}$ while ouabain increased both to an identical extent, although the estimations made here was based on an additional assumption that the relationship shown by Eq. (5) is also applicable to the twitches of the muscles potentiated by the drugs.
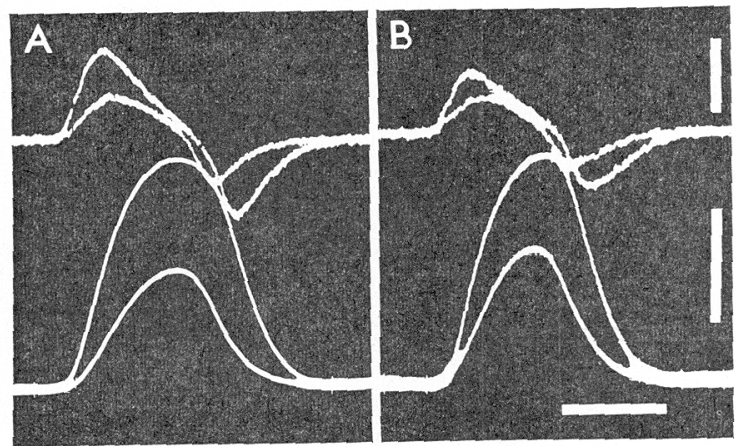

Fig. 4. Potentiation of twitch in bullfrog ventricle produced by 0.16 mM-K Ringer (A) and $50 \%-\mathrm{Na}, 50 \%-\mathrm{Li}$ Ringer (B). Upper traces are differential curves of contraction. In each figure, control and the potentiated state are shown. Upper vertical bar is calibration of $200 \mathrm{mg} / \mathrm{sec}$, lower one, that of $70 \mathrm{mg}$ for A and $40 \mathrm{mg}$ for B. Horizontal bar is calibration of $1 \mathrm{sec}$.

\section{Effects of low-K Ringer and low-Na Ringer on the twitch pattern}

Figure 4 shows the potentiation of twitch produced by $0.16 \mathrm{~mm}-\mathrm{K}$ Ringer and $50 \%$-Na Ringer solution. Both conditions seemed to have almost the same effects. Table 2 summarizes the results obtained from a number of experiments similar to those shown in Fig. 4. It was found that low-K Ringer solution had an action to depress the rate of relaxation of twitch, so that the increase in $V_{r}$. was relatively smaller than that in $V_{c}$, and hence the value of $D$ became significantly smaller than 1. In the experiments of $50 \%$ - Na Ringer solution, choline chloride 


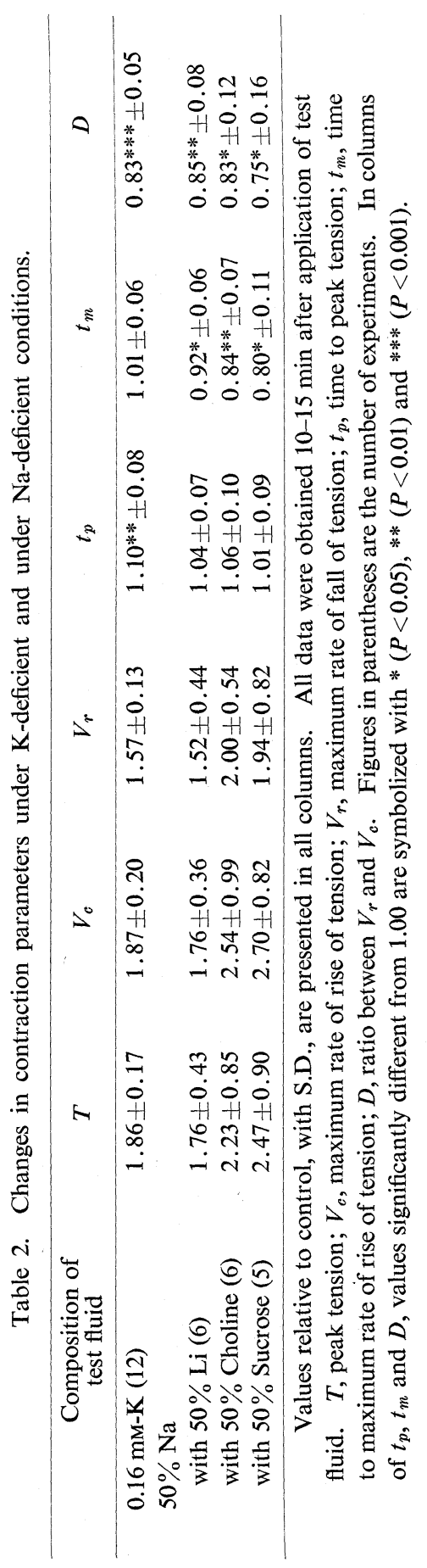


or $\mathrm{LiCl}$ or sucrose was used for substituents and they had almost similar effects. It is well known that low-Na condition inhibits or retards the relaxation of myocardial twitch (NIEDERGERKE and LüTTGAU, 1957; Goto et al., 1972a). In addition, in the present experiments, it was noted that $t_{m}$ significantly decreased under low-Na condition in spite of a slight prolongation in $t_{p}$ (Table 2). The conclusion was that both low-K and low-Na Ringer solution had a similar effect to slow the relaxation of twitch and that low-Na Ringer had an additional effect to decrease $t_{m}$.

\section{DISCUSSION}

The relaxant effect of adrenaline. The interesting feature of the effects of adrenaline examined in the present experiments is that the increase in the rate of fall of tension observed in the muscles potentiated by adrenaline was appreciably greater than both the increase in peak tension and the increase in the rate of rise of tension. Adrenaline seems to have an effect to facilitate the relaxation of twitch, in addition to its well known positive inotropic effect.

Recently, MORAD and ROLETT (1972) demonstrated in cat ventricular muscle which was kept under 'a state of Ca-overload' that catecholamines brought about an increase in relaxation rate and a shortening of time to peak tension during a twitch contraction. According to these authors, such a relaxant effect was detectable under particular conditions where the relaxation rate of twitch was depressed to a certain extent by high stimulation rate or by high-Ca perfusion or by low temperature. Although the abbreviation of myocardial systole due to adrenaline is a classically known phenomenon, it has not been established that adrenaline enhances the rate of relaxation of twitch under 'normal condition.' The present analysis showed quantitatively that adrenaline exerts its relaxant effect during the time course of a single twitch even under 'normal condition,' independent of its potentiating effect.

Adrenaline probably stimulates the calcium sequestering system which includes sarcoplasmic reticulum, mitochondria, and sarcolemma. It has been suggested that the accumulation of cellular cyclic adenosine $3^{\prime}, 5^{\prime}$-monophosphate (c-AMP) produced by catecholamines is fundamentally associated with their positive inotropic effects (WILliAMSON, 1966; ENTMAN et al., 1969; EPSTEIN et al., 1971). Recently, KIRCHBERGER et al. (1972) found that the actions of c-AMP on microsomal $\mathrm{Ca}$ uptake in mammalian myocardium are mediated by c-AMPdependent protein kinase, and they postulated a model which can explain the mode of action of catecholamines on myocardial contractility. In their model, the accumulation of c-AMP induced by catecholamine activates c-AMP-dependent protein kinase, which brings about a rapid uptake of activator $\mathrm{Ca}$ from sarcoplasm into sarcoplasmic reticulum. This train of events, therefore, could explain the relaxation-facilitating effect of catecholamines. If the more rapid uptake of $\mathrm{Ca}$ into intracellular store leads to an increase in the amount of $\mathrm{Ca}$ available for a 
release at subsequent beat, then this action also contributes to the positive inotropism, though an increase in the influx of activator $\mathrm{Ca}$ during action potential can also explain the inotropic effect of catecholamines (GROSSMAN and FURCHGOTT, 1964; ReUTER, 1965; VASSORT et al., 1969). It may still not be safe to apply the results obtained from mammalian heart to frog ventricle, since the specialized sarcotubular system is thought to be poorly developed in frog ventricular muscle (Staley and Benson, 1968; Sommer and Johnson, 1969). However, the present results could be interpreted along the same line discussed above, if the intracellular membrane system, such as sarcoplasmic reticulum, mitochondria, and sarcolem$\mathrm{ma}$, also functions as a Ca-sequestering system in frog hearts.

The inotropic effect of ouabain. In the present conditions, ouabain seemed to have no influence on the mechanism of relaxation and to have only an effect to augment the degree of activation in contraction, thereby causing an increase in the rate of rise of tension and peak tension. The accompanying increase in the rate of fall of tension could be suitably explained by a simple model for the movement of activator $\mathrm{Ca}$ without taking into account, if any, an effect of ouabain on the mechanism of relaxation. Although the exact mechanism by which cardiac glycosides exert their inotropic effects is not yet fully understood (see LEE and KLAUS, 1971), the present results suggest that at least ouabain does not affect the system which remove activator Ca from sarcoplasm. LEE and KLAUS (1971), based on the fact that the effects of cardiac glycosides on Ca uptake of sarcoplasmic reticulum range from stimulation to no effect or to inhibition depending on the investigators and experimental conditions, pointed out that cardiac glycosides have no essential effect on the $\mathrm{Ca}$ transport mechanism of sarcoplasmic reticulum in terms of the $\mathrm{Ca}$ amount taken up in the presence of ATP. The present results are in accord with this view. However, it must be mentioned that the present discussions are based on the results from the experiments in which the concentration of ouabain used was low $\left(10^{-7}-10^{-6} \mathrm{M}\right)$. It is well known that a high dose of cardiac glycosides causes a contracture in myocardium. The mode of action of cardiac glycosides may vary depending on the experimental conditions.

The effects of low-K Ringer and low-Na Ringer solution. The phenomenon that the reduction in $\mathrm{K}$ concentration of Ringer solution potentiates the myocardial contractility is well known since earlier time (RINGER, 1883). In the present experiments, the bullfrog ventricle potentiated by low-K Ringer showed a relatively slow relaxation of twitch. It is known that $\mathrm{K}$-deficient condition interferes with the activity of the membrane Na-K ATPase which is responsible for the cation transport across the membrane (see BonTING, 1970). Such a condition, in time, actually brings about a certain change in the intracellular ionic environment of muscle cells (DESMEDT, 1953; NIEDERGERKE and ORKAND, 1966), and hence may affect the myocardial contractility. However, the present finding that the relaxation-depressant effect of low-K Ringer, as well as its potentiating effect, was observable immediately on application of the fluid to the muscle suggests that these 
effects are not due to a certain cumulative change in the muscle condition which may be produced by the inhibition of Na-K transport system. Recently, some evidences suggesting the existence of an interrelationship between $\mathrm{K}$ ions and the $\mathrm{Ca}$-accumulating ability of cardiac microsome or mitochondria have been reported (KATZ and RePKe, 1967; Dransfeld et al., 1969). Considering all these facts together, it is possible that $\mathrm{K}$ ions, as $\mathrm{Na}$ and $\mathrm{Ca}$ ions, also play a fundamental role in the regulation of myocardial contractility, although the definite conclusion must wait further investigations.

The possible roles which $\mathrm{Na}$ ions play in myocardial excitation-contraction coupling have been discussed extensively by many previous investigators. In frog myocardium, a progressive reduction in the external $\mathrm{Na}$ concentration slows the rate of relaxation in twitch and finally causes a contracture (WILBRANDT and Koller, 1948; Niedergerke and Lüttgau, 1957; Goto et al., 1972a). The present experiments also confirmed the observations quoted above. In addition, it was noted that $t_{m}$ (time to maximum rate of rise of tension) significantly decreased under Na-deficient conditions, $t_{p}$ (time to peak tension) being rather prolonged slightly (Table 2). The nature underlying this phenomenon is unknown at present, but it is of interest to mention that Na-loaded frog ventricular muscle exhibits a similar twitch pattern with rapid onset ( $t_{m}$ decreased) and slow relaxation (EHARA, 1974).

I would like to express my thanks to Prof. M. Goto for his constant encouragement and for reading the manuscript, and to Prof. $\mathrm{H}$. Kawata for his valuable suggestions during the experiments.

\section{REFERENCES}

Antoni, H., JaKob, R., and KaUfmann, R. (1969) Mechanische Reaktionen des Frosch- und Säugetiermyokards bei Varänderung des Aktionspotential-Dauer durch konstante Gleichstromimpulse. Pflügers Arch., 306: 33-57.

Bonting, S. L. (1970) Sodium-potassium activated adenosinetriphosphatases and cation transport. In Membrane and Ion Transport, ed. by BitTaR, E. E. John Wiley and Sons, Ltd., London, Vol. 1, pp. 257-363.

DeSMEDT, J. E. (1953) Electrical activity and intracellular sodium concentration in frog muscle. J. Physiol., 121: 191-205.

Dransfeld, H., GreefF, K., Schorn, A., and Ting, B. T. (1969) Calcium uptake in mitochondria and vesicles of heart and skeletal muscle in presence of potassium, sodium, $\mathrm{k}$ strophanthin and pentobarbital. Biochem. Pharmacol., 18: 1335-1345.

EHARA, T. (1973) Effects of adrenaline and ouabain on the time course of twitch contraction in bullfrog ventricle. J. Physiol. Soc. Japan, 35: 366-367.

EHARA, T. (1974) Late potentiating effect of low-K Ringer on the contractility of the bullfrog ventricle. Jap. J. Physiol., 24: 329-342.

Entman, M. L., Levey, G. S., and Epstein, S. E. (1969) Mechanism of action of epinephrine and glucagon on the canine heart. Circ. Res., 25: 429-438.

Epstein, S. E., Levey, G. S., and Skelton, C. L. (1971) Adenyl cyclase and cyclic AMP; Biochemical links in the regulation of myocardial contractility. Circulation, 43: 437-450. 
Glitsch, H. G., Reuter, H., and Scholz, H. (1970) The effect of internal sodium concentration on calcium fluxes in isolated guinea-pig auricles. J. Physiol., 209: 25-43.

Goto, M., Кiмото, Y., and Kato, Y. (1971) A study on the excitation-contraction coupling of the bullfrog ventricle with voltage clamp technique. Jap. J. Physiol., 21: 159-173.

Goto, M., Кімото, Y., and SuetSugu, Y. (1972a) Membrane currents responsible for contraction and relaxation of the bullfrog ventricle. Jap. J. Physiol., 22: 315-331.

Goто, M., Кімото, Y., SAITo, M., and WADA, Y. (1972b) Tension fall after contraction of bullfrog atrial muscle examined with the voltage clamp technique. Jap. J. Physiol., 22: 637-650.

Grossman, A. and FurchGotT, R. F. (1964) The effects of various drugs on calcium exchange in the isolated guinea-pig left auricle. J. Pharmacol. Exp. Ther., 145: 162-172.

Katz, A. M. and RePKE, D. I. (1967) Sodium and potassium sensitivity of calcium uptake and calcium binding by dog cardiac microsomes. Circ. Res., 21: 767-775.

Kawata, H., Shibata, J., and Goto, M. (1969) A study on the coupling mechanism between action potential and contraction in the frog ventricle. Jap. J. Physiol., 19: 492-508.

Kirchberger, M. A., TAdA, M., Repke, D. I., and Katz, A. M. (1972) Cyclic adenosine 3',5'monophosphate-dependent protein kinase stimulation of calcium uptake by canine cardiac microsomes. J. Mol. Cell. Cardiol., 4: 673-680.

Langer, G. A. (1973) Heart: Excitation-contraction coupling. Ann. Rev. Physiol., 35: 55-86.

LEE, K. S. and KLAUS, W. (1971) The subcellular basis for the mechanism of inotropic action of cardiac glycosides. Pharmacol. Rev., 23: 193-261.

MoRAD, M. and ORKAND, R. K. (1971) Excitation-contraction coupling in frog ventricle: Evidence from voltage clamp studies. J. Physiol., 219: 167-189.

Morad, M. and RoletT, E. L. (1972) Relaxing effects of catecholamines on mammalian heart. J. Physiol., 224: 537-558.

Morad, M. and Trautwein, W. (1968) The effect of duration of the action potential on contraction in the mammalian heart muscle. Pflügers Arch., 299: 66-82.

Niedergerke, R. and LüttGaU, H. C. (1957) Calcium and the contraction of heart. Antagonism between calcium and sodium ions. Nature (Lond.), 179: 1066-1067.

Niedergerke, R. and ORKAND, R. K. (1966) The dependence of the action potential of the frog's heart on the external and intracellular sodium concentration. J. Physiol., 184: 312334.

Reuter, H. (1965) Über die Wirkung von Adrenalin auf den cellulären Ca-Umsatz des Meerschweinchenvorhofs. Arch. Exp. Path. Pharmak., 251: 401-412.

Reuter, H. and Seitz, N. (1968) The dependence of calcium efflux from cardiac muscle on temperature and external ion composition. J. Physiol., 195: 451-470.

RINGER, S. (1883) A further contribution regarding the influence of the different constituents of the blood on the contraction of the heart. J. Physiol., 4: 29-42.

SOMmer, J. R. and Johnson, E. A. (1969) Cardiac muscle. A comparative ultrastructural study with special reference to frog and chicken hearts. Z. Zellforsch. mikrosk. Anat., 98: 437-468.

Staley, N. A. and Benson, E. S. (1968) The ultrastructure of frog ventricular muscle and its relationship to mechanisms of excitation-contraction coupling. J. Cell. Biol., 38: 99-114.

Vassort, G., Rougier, O., Garnier, D., Sauviat, M. P., Coraboeuf, E., and Gargouil, Y. M. (1969) Effects of adrenaline on me mbrane inward currents during the cardiac action potential. Pflügers Arch., 309: 70-81.

Wilbrandt, W. and Koller, H. (1948) Die Calcium-Wirkung am Froschherzen als Funktion des Ionengleichgewichts zwischen Zellmembrane und Umgebung. Helv. Physiol. Pharmac. Acta, 6: 208-221.

Williamson, J. R. (1966) Kinetic studies of epinephrine effects in the perfused rat heart. Pharmacol. Rev., 18: 205-210. 